\title{
Prevalence of Metabolic Syndrome in Patients with Schizophrenia in Korea: A Multicenter Nationwide Cross-Sectional Study
}

\author{
Jung Sun Lee ${ }^{1}$, Jun Soo Kwon², Daeho Kim³ , Sung-Wan Kim, Jae-Jin Kim5, Jong-Hoon Kim \\ Hee Jung Nam ${ }^{7}$, Seunghyong Ryu ${ }^{8}$, II Ho Park ${ }^{9}$, Suk Kyoon $\mathrm{An}^{5}$, Hong-Seok Oh${ }^{10}$, Seunghee Won ${ }^{11}$, \\ Kanguk Lee ${ }^{12}$, Kyu Young Lee ${ }^{13}$, Seung-Hwan Lee ${ }^{14}$, Yu Sang Lee ${ }^{10}$, Jung-Seo $\mathrm{Yi}^{15}$, \\ Kyung Sue Hong ${ }^{8}$, and Yeon Ho Joo ${ }^{1}$ \\ ${ }^{1}$ Department of Psychiatry, University of Ulsan College of Medicine, Asan Medical Center, Seoul, Republic of Korea \\ 2Department of Psychiatry, Seoul National University College of Medicine, Seoul National University Hospital, Seoul, Republic of Korea \\ ${ }^{3}$ Department of Psychiatry, College of Medicine, Hanyang University, Hanyang University Medical Center, Seoul, Republic of Korea \\ ${ }^{4}$ Department of Psychiatry, Chonnam National University Medical School, Chonnam National University Hospital, Gwangju, Republic of Korea \\ ${ }^{5}$ Department of Psychiatry, Yonsei University College of Medicine, Yonsei University Health System, Seoul, Republic of Korea \\ ${ }^{6}$ Department of Psychiatry, Gil Medical Center, Gachon University School of Medicine, Neuroscience Research Institute, Gachon University, \\ Incheon, Republic of Korea \\ ${ }^{7}$ Department of Psychiatry, Seoul Medical Center, Seoul, Republic of Korea \\ ${ }^{8}$ Department of Psychiatry, Sungkyunkwan University School of Medicine, Samsung Medical Center, Seoul, Republic of Korea \\ ${ }^{9}$ Department of Psychiatry \& Behavioral Neuroscience, Catholic Kwandong University, International St. Mary's Hospital, Incheon, Republic of Korea \\ ${ }^{10}$ Yongin Psychiatric Research Institute, Yongin Mental Hospital, Yongin, Republic of Korea \\ ${ }^{11}$ Department of Psychiatry, School of Medicine, Kyungpook National University, Kyungpook National University Hospital, Daegu, Republic of Korea \\ ${ }^{12}$ Department of Psychiatry, Kangwon National University School of Medicine, Kangwon National University Hospital, Chuncheon, Republic of Korea \\ ${ }^{13}$ Department of Psychiatry, Eulji University School of Medicine, Eulji General Hospital, Seoul, Republic of Korea \\ ${ }^{14}$ Department of Psychiatry, Inje University College of Medicine, Ilsan Paik Hospital, Goyang, Republic of Korea \\ ${ }^{15}$ Department of Psychiatry, College of Medicine, Hallym University, Kangnam Sacred Heart Hospital, Seoul, Republic of Korea
}

Objective We designed a nationwide study with limited exclusion criteria to investigate the prevalence of metabolic syndrome (MetS) in Korea and its relationship with antipsychotic medications.

Methods This multicenter, cross-sectional, and observational study included patients diagnosed with schizophrenia or schizoaffective disorder. Sixteen hospitals enrolled 845 patients aged 18 to 65 years prescribed any antipsychotic medication between August 2011 and August 2013. MetS was diagnosed using the criteria of the modified Adult Treatment Panel III of the National Cholesterol Education Program with the Korean abdominal obesity definition (waist circumference $\geq 85 \mathrm{~cm}$ in women, $\geq 90 \mathrm{~cm}$ in men).

Results The prevalence of MetS in all patients was $36.5 \%$ and was significantly higher in men than women (men, 40.8\%; women, $32.2 \%$ ) and was significantly correlated with age [odds ratio (OR) 1.02] and duration of illness (OR 1.03). The prevalence of MetS across antipsychotic drugs in the major monotherapy group was as follows: $18.8 \%$ for quetiapine, $22.0 \%$ for aripiprazole, $33.3 \%$ for both amisulpride and paliperidone, $34.0 \%$ for olanzapine, 35\% for risperidone, $39.4 \%$ for haloperidol, and $44.7 \%$ for clozapine.

Conclusion The prevalence of MetS is very high in patients with schizophrenia or schizoaffective disorder. Screening and monitoring of MetS is also strongly recommended.

Psychiatry Investig 2017;14(1):44-50

Key Words Metabolic syndrome, Antipsychotics, Korean population, Schizophrenia, Schizoaffective disorder.

\section{INTRODUCTION}

Patients with schizophrenia have a reduced life expectancy for several reasons, including increased incidence of accidents, cardiovascular disease (CVD), and infectious disease. ${ }^{1}$ In particular, CVD is one of the most important causes of mortality and is responsible for about $45 \%$ of the excess mortality of schizophrenia. ${ }^{2}$ Patients with schizophrenia show 2-3 times

Received: February 19, 2016 Revised: May 2, 2016 Accepted: June 3, 2016 Available online: July 26, 2016

$\bowtie$ Correspondence: Yeon Ho Joo, MD, PhD

Department of Psychiatry, University of Ulsan College of Medicine, Asan Medical Center, 88 Oylimpic-ro, Songpa-gu, Seoul 05505, Republic of Korea Tel: +82-2-3010-3410, Fax: +82-2-485-8381, E-mail: jooyh@amc.seoul.kr

(ac) This is an Open Access article distributed under the terms of the Creative Commons Attribution Non-Commercial License (http://creativecommons.org/licenses/by-nc/3.0) which permits unrestricted non-commercial use, distribution, and reproduction in any medium, provided the original work is properly cited. 
higher risk of CVD than healthy controls. ${ }^{1}$

Many factors, including poor diet, tobacco smoking, weight gain, and low physical exercise, affect CVD development in patients with schizophrenia. ${ }^{3-5}$ Recently, several medications, especially antipsychotics, have been identified as having a negative impact on the development of CVD. ${ }^{6,7}$ Several comprehensive reviews concluded that atypical antipsychotics significantly increased the risk of certain CVDs, such as diabetes, compared with typical antipsychotics. ${ }^{6,8}$ Some studies also reported a higher prevalence of diabetes and hypertension in patients with schizophrenia than healthy controls. ${ }^{3,9,10}$

This increased prevalence of CVD, diabetes, and hypertension and increased mortality may be partially due to Metabolic Syndrome (MetS). MetS includes five major components: 1) abdominal obesity; 2) hypertension; 3) increased fasting glucose level; 4) hypertriglyceridemia; and 5) decreased highdensity lipoprotein (HDL).

The prevalence of MetS in patients with schizophrenia is 2-4 times higher than in healthy individuals. ${ }^{8,11-13}$ The prevalence of MetS in patients with schizophrenia varies across studies: $35.4 \%$ in the Netherlands, ${ }^{14} 32.3 \%$ in Belgium, ${ }^{15} 40.9 \%$ in the United States CATIE study, ${ }^{12} 22.8 \%$ in Thailand, ${ }^{16} 27.5 \%$ in Japan, ${ }^{17}$ and $31.7 \%$ in Korea. ${ }^{13}$

The causes of this variety in the prevalence include the use of different definitions of MetS, such as that of the Adult Treatment Panel III report (ATP III) of the National Cholesterol Education Program, ${ }^{12,14}$ the modified ATP III, ${ }^{13,15,17}$ and the International Diabetes Federation (IDF). ${ }^{16}$ In addition, some studies of Asian patients used Asian or Korean criteria for abdominal obesity. MetS is also partially dependent on the location, lifestyle, and demographic characteristics of the patients, such as age, gender, and ethnicity. ${ }^{18-20}$ Patients in previous studies had very different demographic and clinical factors, such as mean age, male:female ratio, duration of illness, and prescribed antipsychotic medications. Finally, some studies investigated the prevalence of MetS in a limited number of patients or patients enrolled for other purposes and not for the actual study of this prevalence. Thus, there may have been a selection bias and the results from a limited number of patients or hospitals might not be generalizable.

To overcome these limitations, we designed a nationwide study with minimal exclusion criteria and from multiple psychiatric units across the nation to investigate the prevalence of MetS in Korea and the relationship between psychiatric medication and MetS prevalence.

\section{METHODS}

This study was a multicenter, cross-sectional, and observational study of patients diagnosed with schizophrenia or schizoaffective disorder according to Diagnostic and Statistical Manual of Mental Disorders-IV-Text Revision (DSM-IV-TR) diagnostic criteria. Sixteen hospitals-3 mental hospitals and 13 university-affiliated general hospitals-enrolled patients aged 18 to 65 years that had been prescribed any antipsychotic medication for the treatment of schizophrenia or schizoaffective disorder between August 2011 and August 2013. Of the 892 patients who consented to participate in the study, we excluded 47 due to a lack of information, such as age, gender, blood pressure (BP), waist circumference, or blood laboratory results. Written informed consent was obtained from all patients and this study was approved by the Institutional Review Board of each hospital.

Patient demographic data and histories were obtained from their medical records and by interview. We asked the patients if they had any conditions such as diabetes, dyslipidemia, or hypertension, or were overweight when they enrolled in this study. Based on the patients' reports, we divided these subjects into "patients with no medical disease" and "patients with medical disease". Waist circumference was measured at the umbilical level in a standing position and BP was measured using standard mercury sphygmomanometers or clinically approved automatic BP devices after a 5-minute rest. Plasma HDL cholesterol, triglycerides, and fasting blood glucose were also measured after at least 8-hour fast. MetS was diagnosed with the definitions of the modified ATP III for Korea (three or more of the following five criteria): ${ }^{21}$ waist circumference $\geq 85 \mathrm{~cm}$ in women or $\geq 90$ in men, fasting blood glucose $\geq 100$ $\mathrm{mg} / \mathrm{dL}$ or specific treatment for hyperglycemia, serum triglyceride $\geq 150 \mathrm{mg} / \mathrm{dL}$ or specific treatment for a lipid abnormality, $\mathrm{HDL}<40 \mathrm{mg} / \mathrm{dL}$ in men or $<50 \mathrm{mg} / \mathrm{dL}$ in women or specific treatment for a lipid abnormality, and arterial BP $(\geq 130 / 85)$ or specific treatment for hypertension.

We defined the index date of each patient as the date of blood sampling and the index period as the 12-month period before the index date. We collected information on the dosage and duration of antipsychotics prescribed during the index period. We defined the "monotherapy group" as those patients who took only one antipsychotic drug during the index period. In the monotherapy group, patients were defined as the "major monotherapy group" if they took one of the following antipsychotics: amisulpride, aripiprazole, clozapine, haloperidol, olanzapine, paliperidone, quetiapine, and risperidone.

To investigate the relationship between antipsychotic medication and MetS, we compared the prevalence of MetS in the major monotherapy group according to the antipsychotic medications. In addition, to estimate the effect of the antipsychotic dose on the development of MetS in the major monotherapy group, the doses of the major antipsychotics were converted to the olanzapine equivalent dose. We defined the cumulative 
equivalent dose as the sum of the equivalent doses of the major antipsychotics prescribed to the patient during the index period. We then investigated the effect of the cumulative equivalent dose and mean equivalent dose on the development of MetS in the major monotherapy group. Equivalent ratios of antipsychotics to olanzapine $1 \mathrm{mg}$ were as follows: 0.029 mg for amisulpride, $0.67 \mathrm{mg}$ for aripiprazole, $0.05 \mathrm{mg}$ for clozapine, $2 \mathrm{mg}$ for haloperidol, $2.22 \mathrm{mg}$ for paliperidone, 0.027 $\mathrm{mg}$ for quetiapine, and $3.33 \mathrm{mg}$ for risperidone. ${ }^{22}$

All statistical analyses were performed using STATA (ver. 13; Stata Corp., TX, USA). Comparisons of the prevalence of MetS according to antipsychotic medications or gender were made with the chi-square test. Correlations between MetS and other clinical variables such as age and duration of illness were performed using logistic regression analysis. All statistical analyses used two-tailed test and $\mathrm{p}$ value $<0.05$ was considered to be statistically significant.

\section{RESULTS}

\section{Demographic data and clinical characteristics}

The number of patients in the final analysis was 842 . The demographic and clinical characteristics are presented in Table 1. The mean patient age was $40.2 \pm 11.2$ years (range $18-65$ ) and the number of male patients was 417 (49.5\%). There was no significant difference in age according to gender (men, $39.5 \pm 10.7$; women, $40.9 \pm 11.7, \mathrm{t}=-1.85, \mathrm{p}=0.065$ ). The mean illness duration in all participants was $12.9 \pm 9.4$ years (range $0-44)$. About $26 \%$ patients $(n=219)$ reported that they had one or more medical diseases related to MetS when they enrolled in this study (defined as the medical disease group).

Of the 842 enrolled patients, 27 did not take any antipsychotics during the index period; 14 were drug-naïve patients and the other patients $(n=13)$ took antipsychotics more than 1 year before the index date. In addition, 376 patients (monotherapy group) took only one of 17 antipsychotic medications during the index period. The numbers of patients in the major monotherapy group by the antipsychotics were as follows: risperidone $(n=100)$, clozapine $(n=46)$, olanzapine $(n=46)$, aripiprazole $(n=41)$, paliperidone $(n=39)$, haloperidol $(n=32)$, amisulpride $(\mathrm{n}=18)$, and quetiapine $(\mathrm{n}=16)$. The other patients $(n=38)$ took one of nine antipsychotics (Figure 1, Table 1).

There were no significant differences in the cumulative and mean equivalent doses of antipsychotics in the major monotherapy group between men and women (cumulative equivalent dose: $4426.9 \pm 3161.7 \mathrm{mg}$ vs. $3042.1 \pm 3718.3 \mathrm{mg}, \mathrm{t}=1.03$, $\mathrm{p}=0.31$; mean equivalent dose: $15.0 \pm 8.6 \mathrm{mg}$ vs. $13.6 \pm 9.4 \mathrm{mg}$, $\mathrm{t}=1.4, \mathrm{p}=0.16)$ (Table 1$)$.

\section{Prevalence of MetS}

The prevalence of MetS in all patients was 36.5\% $(n=307)$ and was significantly lower in female patients (women, $32.2 \%$; men, 40.8\%; OR 0.66, 95\% CI 0.50-0.88; age-adjusted p<0.001) and significantly correlated with age (OR 1.02, 95\% CI 1.01-1.04; $\mathrm{p}<0.001$ ) and duration of illness (OR 1.02, 95\% CI $1.01-1.04 ; \mathrm{p}=0.002)$. The prevalence of each component of MetS ranged from $35 \%$ to $50 \%$ (hyperglycemia, $35.0 \%$; hypertriglyceridemia, 38.0\%; HTN, 38.1\%; low HDL, 42.4\%; abdominal obesity, 49.5\%). Abdominal obesity was the most common component for both sexes (men, 51.3\%; women, $47.8 \%)$. There were significant differences in the prevalence of hypertension (men, $44.4 \%$; women, $32.0 \%$; OR $0.56,95 \% \mathrm{CI}$ $0.42-0.75$; age-adjusted $\mathrm{p}<0.001)$ and hypertriglyceridemia (men, 43.9\%; women, 32.2\%; OR 0.59, 95\% CI 0.45-0.78; ageadjusted $\mathrm{p}=0.009$ ) by sex (Table 2 ).

Although 176 (28.3\%) of the 623 patients with no medical

Table 1. Clinical and Demographic characteristics of participants with schizophrenia or schizoaffective disorder

\begin{tabular}{|c|c|c|c|c|}
\hline & Total & Male & Female & $\begin{array}{c}\text { p value } \\
\text { (male vs. female) }\end{array}$ \\
\hline Number of participants & 842 & $417(49.5 \%)$ & $425(50.5 \%)$ & \\
\hline Age (years) & $40.2 \pm 11.2$ & $39.5 \pm 10.7$ & $40.9 \pm 11.7$ & $\mathrm{t}=-1.85, \mathrm{p}=0.065$ \\
\hline Duration of illness (years) & $12.9 \pm 9.4$ & $13.3 \pm 9.5$ & $12.4 \pm 9.3$ & $\mathrm{t}=1.37, \mathrm{p}=0.17$ \\
\hline Number of patients with no medical disease & 623 & $307(73.6 \%)$ & $316(74.4 \%)$ & $\chi^{2}=0.059, \mathrm{p}=0.81$ \\
\hline Number of antipsychotics & & & & $\chi^{2}=0.16, p=0.93$ \\
\hline 0 (drug-naïve or -free group) & 27 & $13(3.1 \%)$ & $14(3.3 \%)$ & \\
\hline 1 (monotherapy group) & 376 & $189(45.3 \%)$ & $187(44.0 \%)$ & \\
\hline 2 or more (combination group) & 439 & $215(51.6 \%)$ & $224(52.7 \%)$ & \\
\hline $\begin{array}{l}\text { Cumulative equivalent dose of major antipsychotics } \\
\text { in the major monotherapy group (mg) }\end{array}$ & $\begin{array}{l}4239.0 \pm 3444.9 \\
\quad(\mathrm{~N}=338)\end{array}$ & $\begin{array}{l}4426.9 \pm 3161.7 \\
\qquad(\mathrm{~N}=173)\end{array}$ & $\begin{array}{l}4042.0 \pm 3718.3 \\
\quad(\mathrm{~N}=165)\end{array}$ & $\mathrm{t}=1.03, \mathrm{p}=0.31$ \\
\hline $\begin{array}{l}\text { Mean equivalent dose of major antipsychotics } \\
\text { in the major monotherapy group (mg) }\end{array}$ & $\begin{array}{l}14.3 \pm 9.0 \\
(\mathrm{~N}=338)\end{array}$ & $\begin{array}{l}15.0 \pm 8.6 \\
(\mathrm{~N}=173)\end{array}$ & $\begin{array}{l}13.6 \pm 9.4 \\
(\mathrm{~N}=165)\end{array}$ & $\mathrm{t}=1.41, \mathrm{p}=0.16$ \\
\hline
\end{tabular}


disease were diagnosed with MetS, 131 (59.8\%) of the 219 patients who reported they had one or more MetS-related medical diseases were diagnosed with MetS.

\section{Relationship between antipsychotic medications and the prevalence of MetS}

The prevalence of MetS was slightly different by the number of antipsychotic medications but it was not statistically significant $(\mathrm{df}=2,839, \mathrm{~F}=0.2, \mathrm{p}=0.762$ ): $33.3 \%$ (drug-naïve or free group), $35.4 \%$ (monotherapy group), $37.6 \%$ (multiple medication group).

Because of the possibility of a different effect of the antipsychotics on MetS, we used only data in the major monotherapy group to investigate the relationship between antipsychotics and MetS. In the major monotherapy group $(n=338)$, the prevalence of MetS according to antipsychotic medications was as follows: $18.8 \%$ for quetiapine, $22.0 \%$ for aripiprazole, $33.3 \%$ for both amisulpride and paliperidone, 34.0\% for olanzapine, 35\% for risperidone, $39.4 \%$ for haloperidol, and $44.7 \%$ for clozapine (Figure 2). The difference of the prevalence of MetS between quetiapine group and aripiprazole group was not significant $\left(\chi^{2}=0.07, p=0.790\right)$. The prevalence of MetS strongly increased with an increase in the cumulative equivalent dose of the seven atypical antipsychotics in the major monotherapy group (OR 1.00012 , 95\% CI 1.000032-1.000204, age- and sex-adjusted $\mathrm{p}=0.007$ ). However, one typical antipsychotic drug (haloperidol) did not show this significant correlation (OR 0.99989, 95\% CI 0.99975-1.00004, age- and sex-adjusted $\mathrm{p}=0.16$ ).

There were no significant correlations found between the development of MetS and the mean equivalent dose of both the seven atypical antipsychotics (OR 1.03, 95\% CI 1.00-1.06, age- and sex-adjusted $\mathrm{p}=0.069)$ and the one typical antipsychotic drug (OR 0.95, 95\% CI 0.90-1.01, age- and sex-adjusted $\mathrm{p}=0.083$ ).

\section{DISCUSSION}

Our present study showed an overall prevalence of MetS in patients with schizophrenia or schizoaffective disorder of $36.5 \%$, with a higher prevalence in male patients $(40.8 \%$ vs. $32.2 \%$ ). In addition, we found that the prevalence of MetS increased significantly with an increase in patient age and duration of illness. When we analyzed the relationship between antipsychotics and MetS in patients prescribed major antipsychotics in the monotherapy group, the prevalence of MetS was lowest with quetiapine (18.8\%) and aripiprazole (22.0\%) and

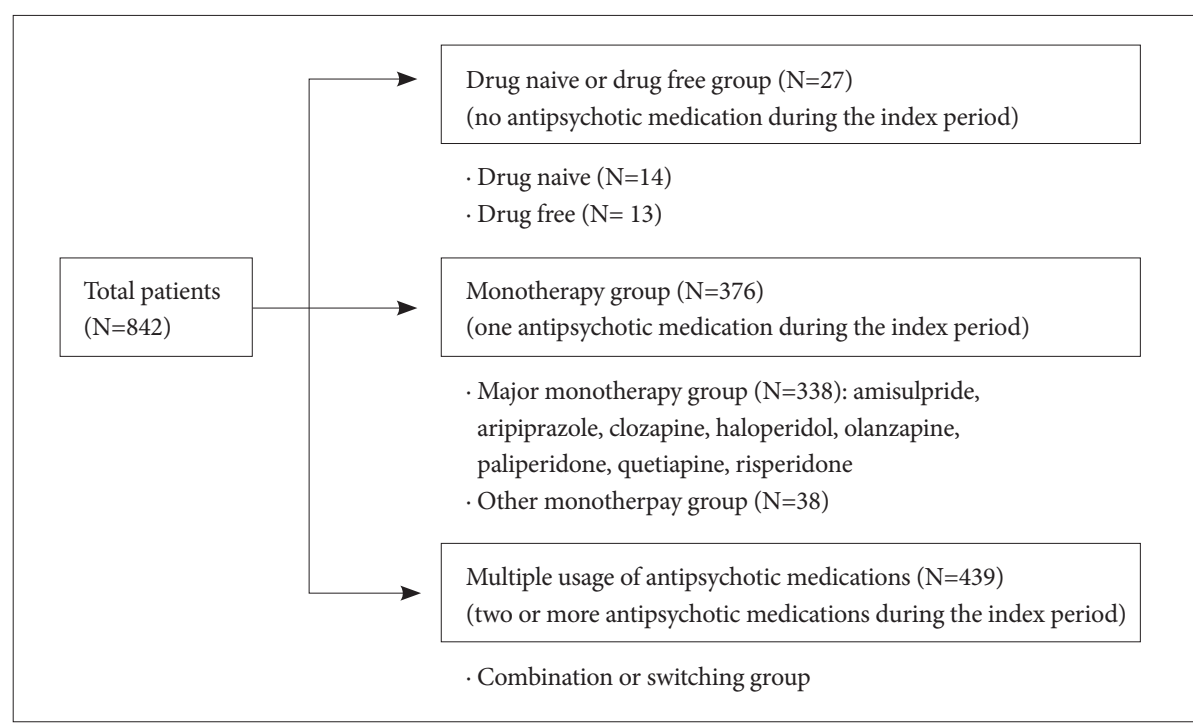

Figure 1. Categorization of participants according to antipsychotic regimen during the index period.

Table 2. Prevalence of metabolic syndrome in patients with schizophrenia or schizoaffective disorder ( $N=842)$

\begin{tabular}{lcccc}
\hline & Total & Male & Female & ${\text { Odds ratio: female/male }(95 \% \text { CI })^{*}}^{\text {Metabolic syndrome }}$ \\
Hyperglycemia & $308(36.5 \%)$ & $171(40.8 \%)$ & $137(32.2 \%)$ & $0.66(0.50-0.88)^{\ddagger}$ \\
Abdominal obesity & $295(35.0 \%)$ & $145(34.7 \%)$ & $150(35.3 \%)$ & $1.00(0.75-1.33)$ \\
Hypertension & $417(49.5 \%)$ & $214(51.3 \%)$ & $203(47.8 \%)$ & $0.85(0.65-1.12)$ \\
Hypertriglyceridemia & $321(38.1 \%)$ & $185(44.4 \%)$ & $136(32.0 \%)$ & $0.56(0.42-0.75)^{\ddagger}$ \\
Low HDL & $320(38.0 \%)$ & $183(43.9 \%)$ & $137(32.2 \%)$ & $0.59(0.45-0.78)^{\dagger}$ \\
\hline
\end{tabular}

${ }^{*}$ age-adjusted logistic regression, ${ }^{\dagger} \mathrm{p}=0.009,{ }^{\ddagger} \mathrm{p}<0.001$. HDL: high-density lipoprotein 


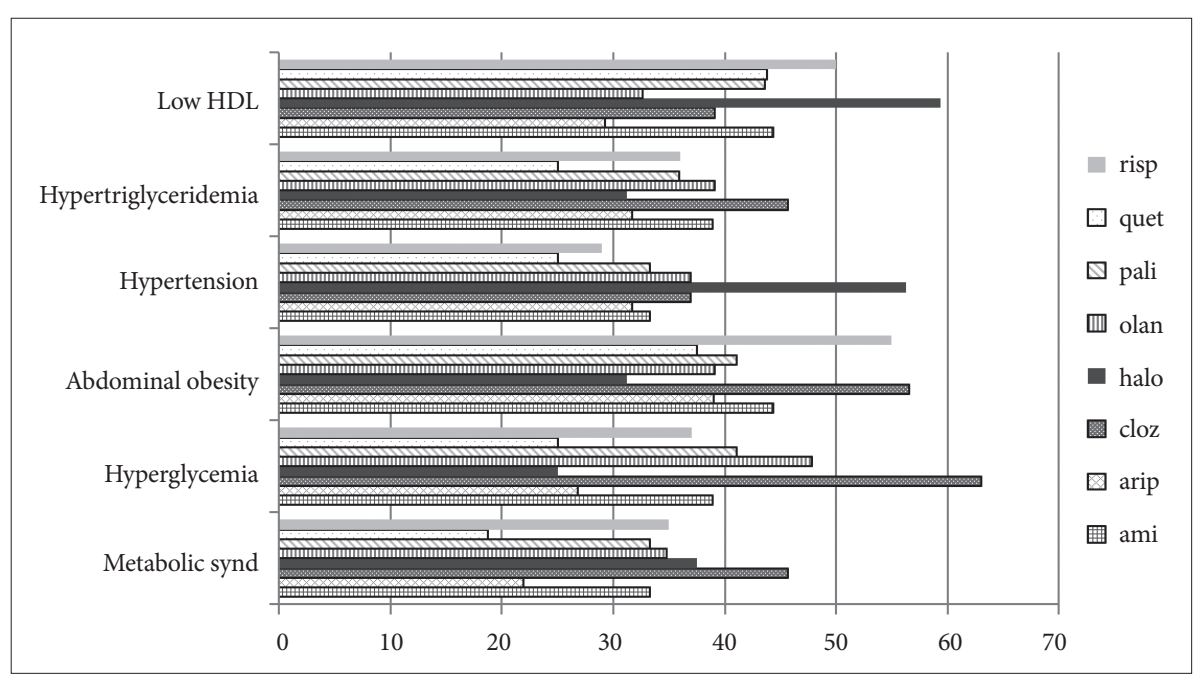

Figure 2. Prevalence of metabolic syndrome and its five components across the major antipsychotics administered during the index period. risp: risperidone, quet: quetiapine, pali: paliperidone, olan: olanzapine, halo: haloperidol, cloz: clozapine, arip: aripiprazole, ami: amisulpride, HDL: high-density lipoprotein. highest with haloperidol (37.5\%) and clozapine (45.7\%). A significant correlation between the cumulative 1-year dose and the development of MetS was found in patients prescribed one of the seven atypical major antipsychotics, not in patients prescribed a typical antipsychotic drug.

The overall prevalence (36.5\%) of MetS in our current study was higher than that reported in other studies with Asian including reports from Thailand (22.8\%), Taiwan $34.9 \%$ and $23.8 \%)$, Japan (27.5\%), and Korea (31.7\%) $)^{13,16,17,23,24}$ and was more comparable to the rates reported from western countries, ${ }^{12}$ although most Asian studies used a lower criterion $(\geq 80$ $\mathrm{cm}$ ) of abdominal obesity than we did $(\geq 85 \mathrm{~cm})$. It is difficult to identify the reasons for this discrepancy because many factors affect the development of MetS, including medication, age, gender, definition of MetS, and lifestyle. However, one of the important causes may be the trend for an increase in obesity and MetS during the past two decades in the Korean healthy population. A population-based study $(n=183,159)$ has reported that the prevalence of obesity in children and adolescents in Korea increased from 5.8\% in 1997 to $9.7 \%$ in $2005 .{ }^{25}$ In addition, according to the population-based surveys performed in 1998, 2001, 2005, and 2007 in Korea, the age-adjusted prevalence of MetS increased significantly from $24.9 \%$ in 1998 to $29.2 \%$ in $2001,30.4 \%$ in 2005 , and $31.3 \%$ in $2007 .{ }^{26}$ Given this trend in healthy people, the results of our study, which enrolled patients from 2011 to 2013 , can be more readily understood.

Our study found that the prevalence of MetS in male patients was eight percentage points higher than that of female patients. Other studies typically showed a higher prevalence of MetS in female patients. ${ }^{12,23,27}$ However, some studies of Asian patients using the modified ATP III criteria also showed a 2.6-8\% higher prevalence of MetS in men. ${ }^{17,23,24}$ This male preponderance of MetS observed in our study and other Asian reports can be explained by the use of different definitions of abdominal obesity. According to Tan et al., ${ }^{28}$ the decreased waist circumference of the modified ATP III for the Asian healthy population increased the crude prevalence of MetS. This effect was more prominent in men ( $7.8 \%$ increase) than in women ( $4.5 \%$ increase). In addition, the use of a stricter definition of abdominal obesity for women $(\geq 85 \mathrm{~cm})$ in our current study than the Asian criterion $(\geq 80 \mathrm{~cm})$ could explain the higher prevalence of MetS in male patients.

Patients with schizophrenia or schizoaffective disorder have several risk factors for MetS. First, smoking is a well-known risk factor for this condition. ${ }^{29}$ Patients with schizophrenia have a higher frequency of smoking than healthy controls or nonpsychotic patients. ${ }^{1,30,31}$ Second, patients with schizophrenia tend to perform little exercise and eat more fat or sugar. ${ }^{5,32}$ These unhealthy lifestyle behaviors can play a role in MetS development in patients with schizophrenia. Third, many studies reported that some atypical antipsychotics, especially olanzapine and clozapine, were associated with an increase in diabetes, weight gain, and MetS. ${ }^{33-36}$ According to a previous meta-analysis of head-to-head comparisons of the metabolic side effects of atypical antipsychotics, ${ }^{37}$ olanzapine produces more weight gain and a greater increase in cholesterol and glucose than other atypical antipsychotics. However, aripiprazole among atypical antipsychotics has shown a relatively lower risk of MetS than other antipsychotics. ${ }^{38-40}$ In line with these reports, the prevalence of MetS was highest in our clozapine group and the patients who had been prescribed aripiprazole had the second lowest prevalence of MetS. Although the lowest prevalence was in the quetiapine group in our study, the size of this group was too small $(n=16)$ to generalize its results.

We found a significant correlation between the cumulative equivalent dose and the increased prevalence of MetS in patients prescribed one of seven major atypical antipsychotics, 
and not in those prescribed a typical antipsychotic drug. However, this finding should be cautiously interpreted because we used only drug information during the 1 year before the index date for analysis and we did not obtain other information on risk factors such as lifestyle. Because MetS occurs insidiously and there are many risk factors of difficult quantification, it is difficult to identify the relationship between the antipsychotic dose and MetS. A literature review has reported a dose-dependent relationship between the metabolic outcomes and serum concentrations only, not the daily administered dose of olanzapine and clozapine. ${ }^{41}$ Osborn et al. ${ }^{42}$ reported a positive correlation between the antipsychotic dosage and cardiovascular mortality. Short-term studies have also reported increased weight gain, fasting glucose, and body fat during short-term atypical antipsychotic treatment. ${ }^{43,44}$

Some patients in our study took anti-depressant or mood stabilizers longer than 30 days during the index period (respectively, 157 and 149 patients). These medications have variable and inconsistent effects on MetS. Although most SSRI except paroxetine have a neutral effect on the development of the side effects related to MetS, paroxetine, venlafaxine, and mirtazapine were associated with the increase of these side effects. ${ }^{45}$ Bupropion is related to the decreased weight. ${ }^{46}$ Our study showed no significant difference of the rate of MetS between the patients who took anti-depressant longer than 30 days and the patients who did not (respectively, $31.8 \%$ vs. $37.5 \%, \mathrm{df}=1,840, \mathrm{~F}=1.77, \mathrm{p}=0.183$ ). Regarding to mood stabilizers, topiramate was related to the decreased weight, ${ }^{47,48}$ while valproate, in contrast, was associated with increased weight gain. ${ }^{49}$ We could not find the significant effect of mood stabilizers on MetS by comparison between the patients who took mood stabilizers longer than 30 days and the patients who did not (prevalence of Mets: $36.2 \%$ vs. $36.5 \%$, respectively, $\mathrm{df}=1,840$, $\mathrm{F}=0.00, \mathrm{p}=0.951)$.

Our study had several limitations. First, although we tried to enroll patients who would be representative of the entire Korean population with schizophrenia or schizoaffective disorder, there was the possibility of a selection bias due to the requirement for written informed consent. However, we estimated the prevalence of MetS from data on 842 patients, which is about $0.74 \%$ of the estimated 114,222 total number of schizophrenia patients in Korea according to a 2011 nationwide epidemiological survey of mental disorders. ${ }^{50}$ Second, we cannot conclude that our findings on the effects of antipsychotic medication on MetS indicate causality because we could not obtain complete information on the antipsychotic medication prescribed to patients after onset and psychiatrists might have prescribed low-risk medications to patients at high risk of MetS development. Finally, information on prescribed medications for dyslipidemia, hypertension, diabetes, or obesity were not precisely gathered.

Notwithstanding these limitations, our current study has confirmed the high prevalence of MetS in patients with schizophrenia or schizoaffective disorder and that this prevalence differs among antipsychotic medications. In addition, most patients diagnosed with MetS in our study cohort did not know they had it before participation. Therefore, patients who are prescribed antipsychotics should be routinely screened.

\section{Acknowledgments}

This study was supported by Korea Otsuka Pharmaceuticals.

\section{REFERENCES}

1. Brown S, Inskip H, Barraclough B. Causes of the excess mortality of schizophrenia. Br J Psychiatry 2000;177:212-217.

2. Osby U, Correia N, Brandt L, Ekbom A, Sparén P. Mortality and causes of death in schizophrenia in Stockholm county, Sweden. Schizophr Res 2000;45:21-28.

3. Dixon L, Weiden P, Delahanty J, Goldberg R, Postrado L, Lucksted A, et al. Prevalence and correlates of diabetes in national schizophrenia samples. Schizophr Bull 2000;26:903-912.

4. McCreadie R, Macdonald E, Blacklock C, Tilak-Singh D, Wiles D, Halliday J, et al. Dietary intake of schizophrenic patients in Nithsdale, Scotland: case-control study. BMJ 1998;317:784-785.

5. Brown S, Birtwistle J, Roe L, Thompson C. The unhealthy lifestyle of people with schizophrenia. Psychol Med 1999;29:697-701.

6. De Hert M, Detraux J, van Winkel R, Yu W, Correll CU. Metabolic and cardiovascular adverse effects associated with antipsychotic drugs. Nat Rev Endocrinol 2011;8:114-126.

7. Leucht S, Komossa K, Rummel-Kluge C, Corves C, Hunger H, Schmid F, et al. A meta-analysis of head-to-head comparisons of second-generation antipsychotics in the treatment of schizophrenia. Am J Psychiatry 2009;166:152-163.

8. De Hert M, Schreurs V, Vancampfort D, van Winkel R. Metabolic syndrome in people with schizophrenia: a review. World Psychiatry 2009; 8:15-22.

9. Sernyak MJ, Leslie DL, Alarcon RD, Losonczy MF, Rosenheck R. Association of diabetes mellitus with use of atypical neuroleptics in the treatment of schizophrenia. Am J Psychiatry 2002;159:561-566.

10. Bresee LC, Majumdar SR, Patten SB, Johnso JA. Prevalence of cardiovascular risk factors and disease in people with schizophrenia: a population-based study. Schizophr Res 2010;117:75-82.

11. Saari KM, Lindeman SM, Viilo KM, Isohanni MK, Järvelin MR, Laurén $\mathrm{LH}$, et al. A 4-fold risk of metabolic syndrome in patients with schizophrenia: the Northern Finland 1966 Birth Cohort study. J Clin Psychiatry 2005;66:559-563.

12. McEvoy JP, Meyer JM, Goff DC, Nasrallah HA, Davis SM, Sullivan L, et al. Prevalence of the metabolic syndrome in patients with schizophrenia: baseline results from the Clinical Antipsychotic Trials of Intervention Effectiveness (CATIE) schizophrenia trial and comparison with national estimates from NHANES III. Schizophr Res 2005;80:1932.

13. Lee NY, Kim SH, Jung DC, Kim EY, Yu HY, Sung KH, et al. The prevalence of metabolic syndrome in Korean patients with schizophrenia receiving monotherapies with aripiprazole, olanzapine or risperidone. Prog Neuropsychopharmacol Biol Psychiatry 2011;35:1273-1278.

14. Schorr SG, Slooff CJ, Bruggeman R, Taxis K. The incidence of metabolic syndrome and its reversal in a cohort of schizophrenic patients followed for one year. J Psychiatr Res 2009;43:1106-1111.

15. De Hert MA, van Winkel R, Van Eyck D, Hanssens L, Wampers M, Scheen A, et al. Prevalence of the metabolic syndrome in patients with 
schizophrenia treated with antipsychotic medication. Schizophr Res 2006;83:87-93.

16. Srisurapanont M, Likhitsathian S, Boonyanaruthee V, Charnsilp C, Jarusuraisin N. Metabolic syndrome in Thai schizophrenic patients: a naturalistic one-year follow-up study. BMC Psychiatry 2007;7:14.

17. Sugawara N, Yasui-Furukori N, Sato Y, Umeda T, Kishida I, Yamashita $\mathrm{H}$, et al. Prevalence of metabolic syndrome among patients with schizophrenia in Japan. Schizophr Res 2010;123:244-250.

18. Ford ES, Giles WH, Dietz WH. Prevalence of the metabolic syndrome among US adults: findings from the third national health and nutrition examination survey. JAMA 2002;287:356-359.

19. Eckel RH, Grundy SM, Zimmet PZ. The metabolic syndrome. Lancet 2005;365:1415-1428.

20. Park YW, Zhu S, Palaniappan L, Heshka S, Carnethon MR, Heymsfield SB. The metabolic syndrome: prevalence and associated risk factor findings in the US population from the Third National Health and Nutrition Examination Survey, 1988-1994. Arch Intern Med 2003;163: 427-436.

21. Lee SY, Park HS, Kim DJ, Han JH, Kim SM, Cho GJ, et al. Appropriate waist circumference cutoff points for central obesity in Korean adults. Diabetes Res Clin Pract 2007;75:72-80.

22. Gardner DM, Murphy AL, O apos Donnell H, Centorrino F, Baldessarini RJ. International consensus study of antipsychotic dosing. Am J Psychiatry 2010;167:686-693.

23. Huang MC, Lu ML, Tsai CJ, Chen PY, Chiu CC, Jian DL, et al. Prevalence of metabolic syndrome among patients with schizophrenia or schizoaffective disorder in Taiwan. Acta psychiatr Scand 2009;120:274280.

24. Bai YM, Chen TT, Yang WS, Chi YC, Lin CC, Liou YJ, et al. Association of adiponectin and metabolic syndrome among patients taking atypical antipsychotics for schizophrenia: a cohort study. Schizophr Res 2009;111:1-8.

25. Oh KW, Jang MJ, Lee NY, Moon JS, Lee CG, Yoo MH, et al. Prevalence and trends in obesity among Korean children and adolescents in 1997 and 2005. Korean J Pediatr 2008;51:950-955.

26. Lim S, Shin H, Song JH, Kwak SH, Kang SM, Won Yoon J, et al. Increasing prevalence of metabolic syndrome in Korea: the Korean $\mathrm{Na}-$ tional Health and Nutrition Examination Survey for 1998-2007. Diabetes Care 2011;34:1323-1328.

27. Deuschle M, Paul F, Brosz M, Bergemann N, Franz M, KammererCiernioch J, et al. Assessment of cardiovascular disease risk in patients with schizophrenia spectrum disorders in German psychiatric hospitals: results of the pharmacoepidemiologic CATS study. Soc Psychiatry Psychiatr Epidemiol 2013;48:1283-1288.

28. Tan CE, Ma S, Wai D, Chew SK, Tai ES. Can we apply the National Cholesterol Education Program Adult Treatment Panel definition of the metabolic syndrome to Asians? Diabetes Care 2004;27:1182-1186.

29. Eberly LE, Prineas R, Cohen JD, Vazquez G, Zhi X, Neaton JD, et al. Metabolic syndrome: risk factor distribution and 18-year mortality in the multiple risk factor intervention trial. Diabetes Care 2006;29:123130 .

30. de Leon J, Dadvand M, Canuso C, White AO, Stanilla JK, Simpson GM. Schizophrenia and smoking: an epidemiological survey in a state hospital. Am J Psychiatry 1995;152:453-455.

31. de Leon J, Diaz FJ. A meta-analysis of worldwide studies demonstrates an association between schizophrenia and tobacco smoking behaviors. Schizophr Res 2005;76:135-157.

32. Amani R. Is dietary pattern of schizophrenia patients different from healthy subjects? BMC Psychiatry 2007;7:15.

33. Meyer JM, Koro CE. The effects of antipsychotic therapy on serum lipids: a comprehensive review. Schizophr Res2004;70:1-17.

34. De Hert M, Schreurs V, Sweers K, Van Eyck D, Hanssens L, Sinko S, et al. Typical and atypical antipsychotics differentially affect long-term incidence rates of the metabolic syndrome in first-episode patients with schizophrenia: a retrospective chart review. Schizophr Res 2008; 101:295-303.

35. Meyer JM, Davis VG, Goff DC, McEvoy JP, Nasrallah HA, Davis SM, et al. Change in metabolic syndrome parameters with antipsychotic treatment in the CATIE Schizophrenia Trial: prospective data from phase 1. Schizophr Res 2008;101:273-286.

36. Wampers M, Hanssens L, van Winkel R, Heald A, Collette J, Peuskens $\mathrm{J}$, et al. Differential effects of olanzapine and risperidone on plasma adiponectin levels over time: results from a 3-month prospective openlabel study. Eur Neuropsychopharmacol 2012;22:17-26.

37. Rummel-Kluge C, Komossa K, Schwarz S, Hunger H, Schmid F, Lobos $\mathrm{CA}$, et al. Head-to-head comparisons of metabolic side effects of second generation antipsychotics in the treatment of schizophrenia: a systematic review and meta-analysis. Schizophr Res 2010;123:225-233.

38. van Winkel R, De Hert M, Wampers M, Van Eyck D, Hanssens L, Scheen A, et al. Major changes in glucose metabolism, including new-onset diabetes, within 3 months after initiation of or switch to atypical antipsychotic medication in patients with schizophrenia and schizoaffective disorder. J Clin Psychiatry 2008;69:472-479.

39. L'Italien GJ, Casey DE, Kan HJ, Carson WH, Marcus RN. Comparison of metabolic syndrome incidence among schizophrenia patients treated with aripiprazole versus olanzapine or placebo. J Clin Psychiatry 2007;68:1510-1516.

40. Lin CC, Bai YM, Wang YC, Chen TT, Lai IC, Chen JY, et al. Improved body weight and metabolic outcomes in overweight or obese psychiatric patients switched to amisulpride from other atypical antipsychotics. J Clin Psychopharmacol 2009;29:529-536.

41. Simon V, van Winkel R, De Hert M. Are weight gain and metabolic side effects of atypical antipsychotics dose dependent? A literature review. J Clin Psychiatry 2009;70:1041-1050.

42. Osborn DP, Levy G, Nazareth I, Petersen I, Islam A, King MB. Relative risk of cardiovascular and cancer mortality in people with severe mental illness from the United Kingdom's General Practice Research Database. Arch Gen Psychiatry 2007;64:242-249.

43. Eder U, Mangweth B, Ebenbichler C, Weiss E, Hofer A, Hummer M, et al. Association of olanzapine-induced weight gain with an increase in body fat. Am J Psychiatry 2001;158:1719-1722.

44. Chen JJ, Chan HY, Chen CH, Gau S, Hwu HG. Risperidone and olanzapine versus another first generation antipsychotic in patients with schizophrenia inadequately responsive to first generation antipsychotics. Pharmacopsychiatry 2012;45:64-71.

45. McIntyre RS, Park KY, Law CW, Sultan F, Adams A, Lourenco MT, et al. The association between conventional antidepressants and the metabolic syndrome: a review of the evidence and clinical implications. CNS Drugs2010;24:741-753.

46. Bhuvaneswar CG, Baldessarini RJ, Harsh VL, Alpert JE. Adverse endocrine and metabolic effects of psychotropic drugs: selective clinical review. CNS Drugs 2009;23:1003-1021.

47. Hahn MK, Remington G, Bois D, Cohn T. Topiramate augmentation in clozapine-treated patients with schizophrenia: clinical and metabolic effects. J Clin Psychopharmacol 2010;30:706-710.

48. Hahn MK, Cohn T, Teo C, Remington G. Topiramate in schizophrenia: a review of effects on psychopathology and metabolic parameters. Clin Schizophr Relat Psychoses 2013;6:186-196.

49. Correll CU, Carlson HE. Endocrine and metabolic adverse effects of psychotropic medications in children and adolescents. J Am Acad Child Adolesc Psychiatry 2006;45:771-791.

50. Cho M. The Epidemiological Survey of Mental Disorders in Korea 2011. Ministry of Health and Welfare 2012;1-439. 